\title{
O secretário executivo na gestão da internacionalização da educação superior brasileira
}

The executive assistant in the management of internationalization of Brazilian higher education

\section{El secretario ejecutivo em la gestión de la internacionalización de la educación superior brasileña}

Fernanda Geremias Leal ${ }^{1}$

Raul Oliveira Paes²

Mário César Barreto Moraes ${ }^{1}$

DOI: http://dx.doi.org/10.20435/serie-estudos.v0i0.1370

Resumo: No Brasil, a internacionalização da educação superior se inicia e se desenvolve a partir do fomento do Estado, com maior projeção nas universidades públicas. Sobretudo após 2010, esse processo adquiriu maior abrangência e intencionalidade no domínio da gestão dessas instituições. Dado esse contexto, o objetivo do presente artigo é conhecer o espaço que o profissional de Secretariado Executivo ocupa na gestão da internacionalização das universidades federais brasileiras. Para tanto, desenvolve-se uma pesquisa qualitativa junto a dezesseis secretários executivos que atuam nos setores responsáveis pela gestão das relações internacionais em tais contextos. As análises integradas de três dimensões - 1. contexto de atuação; 2 . entendimento sobre internacionalização; 3. (auto)avaliação da participação na gestão do processo - possibilitam evidenciar que, do ponto de vista instrumental, tanto o contexto promissor de atuação dos secretários executivos quanto a visão pragmática que eles têm do processo e a (auto)avaliação que fazem de sua participação são altamente funcionais ao "desenvolvimento" da internacionalização no nível institucional. Todavia questiona-se a possibilidade de que eles contribuam com iniciativas de inserção internacional desvinculadas da racionalidade dominante.

Palavras-chave: secretário executivo; internacionalização; educação superior.

Abstract: In Brazil, the internationalization of higher education begins and is developed with the incentive of the State, with a greater projection in public universities. Especially after 2010, this process got greater scope and intentionality in the management of these institutions. Given this context, the aim of this article is to understand the space that executive assistants occupy in the

\footnotetext{
1 Universidade do Estado de Santa Catarina (UDESC), Florianópolis, Santa Catarina, Brasil.

2 Universidade Federal do Pará (UFPA), Belém, Pará, Brasil.
} 
internationalization management of Brazilian federal universities. For that, we conduct a qualitative research with sixteen executive assistants who work in the departments responsible for managing international relations in such contexts. The integrated analysis of three dimensions - 1. context of action; 2 . understanding about internationalization; 3. (self)assessment of their participation in the process management - demonstrate that, from an instrumental perspective, the promising context for executive assistants' performance, their pragmatic view of the internationalization process, and the (self)evaluation they make about their participation are highly functionals to the "development" of internationalization at the institutional level. However, we question the possibility that they contribute to initiatives of international insertion that are detached from the dominant rationality.

Keywords: executive assistant; internationalization; higher education.

Resumen: En Brasil, la internacionalización de la educación superior comienza y se desarrolla a partir de la promoción del Estado, con mayor proyección en las universidades públicas. Especialmente después de 2010, el proceso adquirió un mayor alcance e intencionalidad en la gestión de estas instituciones. Dado este contexto, el objetivo de este artículo es conocer el espacio que el profesional de Secretariado Ejecutivo ocupa en la gestión de la internacionalización de las universidades federales brasileñas. Con este fin, se lleva a cabo una investigación cualitativa con dieciséis secretarios ejecutivos que trabajan en los sectores responsables de gestionar las relaciones internacionales en tales contextos. Los análisis integrados de tres dimensiones - 1. contexto de acción; 2. comprensión sobre la internacionalización; 3. (autoevaluación) de la participación en la gestión del proceso - permiten mostrar que, desde un punto de vista instrumental, tanto el contexto prometedor del desempeño de los secretarios ejecutivos cuanto su visión pragmática del proceso y la (auto)evaluación que hacen de su participación son altamente funcionales para el "desarrollo" de la internacionalización en nivel institucional. Sin embargo, se cuestiona la posibilidad de que contribuyan a iniciativas de inserción internacional separadas de la racionalidad dominante.

Palabras clave: secretario ejecutivo; internacionalización; educación superior.

\section{INTRODUÇÃO}

A despeito da ampla trajetória de relações internacionais na educação superior brasileira, é a partir dos anos 2000 que os significados e os anseios atrelados à internacionalização alcançam um novo patamar no país. Como reflexo dos desenvolvimentos observados no centro do sistema mundial, esse processo se torna cada vez mais intencional, abrangente e se fortalece de modo a influenciar os valores e a razão de ser da instituição universidade. Com o impulso de programas governamentais como o Ciência sem Fronteiras (CsF), o Idiomas sem Fronterias (IsF) e, sobretudo, o Programa Institucional de Internacionalização (CapesPrlnt) - implementado pelo Governo Federal em 2018 -, a internacionalização adquire centralidade no domínio da gestão universitária das universidades públicas federais, o que suscita desenvolvimento de estudos que se ocupem de compreender os efeitos dessa institucionalização. 
O objetivo deste artigo é conhecer o espaço que o profissional de Secretariado Executivo ocupa na gestão da internacionalização das universidades públicas federais brasileiras. O cargo integra a carreira dos Servidores TécnicoAdministrativos em Educação (STAE) desde a implantação do Plano de Carreira dos Cargos Técnico-Administrativos em Educação (PCCTAE), em 2005. Hoje, há aproximadamente dois mil ocupantes do cargo nas Instituições Federais de Ensino Superior (IFES), que atuam nos setores acadêmicos e administrativos da estrutura universitária (LEAL; SOUZA; MOREIRA, 2018).

Autores como Said et al. (2015), Stafford e Taylor (2016) e Hunter (2018) apontam para a quantidade restrita de pesquisas que tratam da gestão da internacionalização na educação superior, apesar dos indícios de que as lideranças institucionais representam fatores críticos em todos os estágios desse processo (CHILDRESS, 2009). No contexto brasileiro, Leal, Céspedes e Stallivieri (2017) dão início a essa discussão e diagnosticam o perfil dos gestores de cooperação internacional em 46 universidades públicas federais vinculadas à Associação Brasileira de Educação Internacional (Faubai). Leal e Moraes (2017), por sua vez, confrontam as competências apresentadas pela literatura como necessárias à gestão da internacionalização com as competências abrangidas pelo perfil profissional do secretário executivo. Tais autores inferem que, ao menos em teoria, o secretário executivo apresenta condições de contribuir com o desenvolvimento do processo. Todavia, até o momento, não há estudos que analisem o espaço que esse profissional tem, de fato, ocupado no contexto da gestão da internacionalização institucional.

Desenvolve-se uma pesquisa qualitativa e descritiva com dezesseis secretários executivos que atuam nos setores responsáveis pelas relações internacionais institucionais em doze universidades públicas federais vinculadas à Faubai. $O$ texto está organizado em quatro partes, além desta introdução. A primeira trata da evolução do conceito e das práticas de internacionalização na educação superior, bem como das perspectivas de atuação do secretário executivo na gestão institucional desse processo. A segunda detalha o percurso metodológico que possibilitou o desenvolvimento da pesquisa, enquanto a terceira descreve os dados obtidos e os resultados alcançados. A quarta parte apresenta as considerações finais e as referências. 


\section{REFERENCIAL TEÓRICO}

\subsection{Internacionalização da educação superior: da mobilidade acadêmica à institucionalização do processo}

O aumento da importância conferida ao conhecimento no desenvolvimento das economias, associado à expansão da competitividade em nível mundial, tem induzido a internacionalização da educação superior a projetar-se como caminho para que os países, as universidades e os indivíduos se integrem de forma ativa à economia global do conhecimento (LEAL, 2019). Entre o fim dos anos 1990 e início dos anos 2000, quando os estudos seminais sobre o tema foram publicados, já se apontava para a complexidade inerente ao fenômeno, tendo em vista a diversidade de estágios, formas de manifestação, motivações conflitantes (rationales), atores e consequências a ele atrelados. Tal complexidade induzia a uma falta de consenso sobre o seu significado (KNIGHT, 2012) . $^{3}$

O caráter circunstancial da internacionalização é enfatizado por Whitsed e Green (2014), que, ao desenvolverem uma crítica às definições comumente propostas para o fenômeno, afirmam que se trata de um construto multifocal com significado contextual específico; um conjunto de atividades agrupadas e classificadas com base nas qualidades (expectativas, experiências etc.) daqueles que o rotulam.

Há, portanto, fatores ambientais, organizacionais e intraorganizacionais que influenciam a internacionalização da educação superior (SEEBER et al., 2016), o que corresponde a reconhecer que as instituições universitárias dispõem de objetivos próprios relacionados a esse processo, que são influenciados pelas bases cognitivas e orientadoras de seus agentes internos. Como Maringe, Foskett e Woodfield (2013) observam, existem pelo menos quatro grandes áreas de criação de valor que as universidades almejam alcançar com a internacionalização: a) valor estratégico e simbólico; b) valor de criação de conhecimento (capital social e intelectual); c) valor de integração cultural; e d) valor de mercado global.

\footnotetext{
3 Knight (2004) elaborou a definição mais difundida para internacionalização da educação superior: o processo de integração das dimensões internacional, intercultural e global aos propósitos, às funções primárias e à entrega da educação superior, com vistas ao alcance ou aprimoramento de objetivos que transitam entre socioculturais, políticos, acadêmicos, econômicos, mercadológicos, entre outros.
} 
O fato é que, seja no contexto global, seja no contexto regional, nacional, institucional ou individual, a internacionalização é, hoje, um dos fatores que mais criticamente têm afetado a educação superior no mundo (DE WIT, 2019). As análises mais recentes sobre o fenômeno possibilitam apontar para pelo menos três grandes desenvolvimentos que merecem atenção. O primeiro diz respeito a um maior reconhecimento de que, ao lado das oportunidades que a internacionalização oferece, há uma série de questões políticas e éticas que são contraditórias e contestáveis (STEIN, 2017). Em grande medida, tais questões se relacionariam à maior inserção da educação superior em um paradigma econômico - em parte resultante da sua perda de prioridade nas políticas de Estado (SOUSA SANTOS, 2011) - que estaria induzindo as rationales econômicas/mercadológicas da internacionalização a se sobressaírem às demais (acadêmicas, socioculturais, políticas, humanitárias etc.). Trata-se, em resumo, do estreito vínculo entre internacionalização e neoliberalismo (BAMBERGER; MORRIS; YEMINI, 2019) ou do avanço da "competição" em detrimento da "cooperação" (DE WIT, 2019).

O segundo desenvolvimento, amplamente associado ao primeiro, amparase da constatação de que a internacionalização da educação superior avança de forma hegemônica, em conformidade com a cultura e os valores ocidentais/ eurocêntricos, que determinam, por exemplo, o que é um "cidadão global", o que é "excelência", quais são as "competências" a serem desenvolvidas nos estudantes; qual a "língua franca" da internacionalização e da ciência. As epistemologias e teorias abarcadas para tratar do tema variam significativamente, sendo que as mais críticas inserem o fenômeno na matriz cultural do poder colonial (SHAHJAHAN, 2016; STEIN, 2017; LEAL; MORAES, 2018; LEAL; MORAES, OREGIONI, 2018; MWANGI et al., 2018).

O terceiro desenvolvimento, por fim, refere-se à evolução do conceito e das práticas de internacionalização. Em termos conceituais, o fenômeno tem sido cada vez mais definido como "abrangente"; um imperativo que "molda o ethos e os valores institucionais e envolve todo o empreendimento universitário" (HUDZIK, 2011, p. 6, tradução nossa). Assim, em vez de ser indiscriminadamente associado a um de suas dimensões, a exemplo da Mobilidade Acadêmica Internacional (MAI), passa a representar mudanças transversais na instituição universitária. Exemplo desse desenvolvimento é a bifurcação da internacionalização em dois pilares distintos: "at home" e "abroad" (KNIGHT; DE WIT, 2018), bem como a 
transição de um foco nos indivíduos, a exemplo dos programas governamentais de MAl historicamente promovidos em diversos sistemas de educação superior do mundo, para um foco direto nas universidades de pesquisa como meio para inserir-se "ativamente" no contexto da "economia global do conhecimento" (PROLO et al., 2019).

\subsection{PERSPECTIVAS DE ATUAÇÃO DO SECRETÁRIO EXECUTIVO NA GESTÃO DA INTERNACIONALIZAÇÃO DA EDUCAÇÃO SUPERIOR}

A despeito da crescente popularidade da internacionalização como um tema de pesquisa e do reconhecimento geral de que esse fenômeno tem (re)orientado o caráter e os valores institucionais da universidade, até o presente momento poucos estudos têm se preocupado com a gestão desse processo no nível institucional ou com o papel que os agentes administrativos desempenham nesse contexto (SAID et al., 2015; HUNTER, 2018). Autores que analisaram a internacionalização da educação superior a partir de lentes estratégicas observam que os gestores universitários desempenham funções críticas em todas as fases do processo, sobretudo no que diz respeito às decisões políticas e à implementação dos planos institucionais de internacionalização. Tais planos, segundo Childress (2009), servem como mecanismo para a "conscientização" da comunidade universitária; veículo para estimular o engajamento de "participantes-chave"; e roteiro para a operacionalização da estratégia definida.

No Brasil, discussões sobre a gestão institucional da internacionalização da educação superior são incipientes. Leal, Céspedes e Stallivieri (2017) fazem um diagnóstico do perfil dos gestores de cooperação internacional em 46 universidades públicas federais brasileiras e identificam aspectos positivos ao avanço do processo nesse domínio, a exemplo do posicionamento dos setores de relações internacionais nas estruturas universitárias e as experiências dos ocupantes do cargo. Os problemas identificados, por sua vez, abrangem mudanças constantes no cargo; acúmulo de funções; formação em áreas distantes do contexto de atuação; e falta de participação em capacitações sobre internacionalização.

Diante das demandas relacionadas à internacionalização nas universidades federais brasileiras, bem como da quantidade significativa de secretários executivos que atuam nesse contexto, Leal e Moraes (2018) investigam se esse profissional apresenta competências contributivas à gestão da internacionalização. Os autores 
inferem que, ao menos em teoria, o secretário executivo apresenta diversas convergências nesse sentido, tais como a interdisciplinaridade do seu perfil; os conteúdos contemplados pela sua formação e a sua caracterização como assessor, consultor, gestor e empreendedor.

De fato, o balanço da literatura sobre a atuação do secretário executivo na gestão universitária pública possibilita inferir que, apesar as dificuldades relacionadas, sobretudo, à falta de aproveitamento do seu potencial de contribuição -, ele se destaca e é reconhecido por sua "produtividade, capacidade de interpretação de situações, intervenção e tomada de decisão, entre outros aspectos relevantes ao aperfeiçoamento da gestão universitária" (LEAL; SOUZA; MOREIRA, 2018, p. 65). Relativamente ao seu papel no contexto da internacionalização, restam estudos empíricos que analisem o espaço que ele ocupa.

\section{PROCEDIMENTOS METOdOLÓGICOS}

O estudo caracterizou-se como qualitativo e descritivo. Desenvolveu-se uma pesquisa de campo com secretários executivos que atuam nos setores responsáveis pela gestão das relações internacionais institucionais (pró-reitorias, secretarias, diretorias etc.) das universidades públicas federais vinculadas à Faubai. Os seguintes aspectos definiram o recorte da pesquisa: 1. Historicamente, a internacionalização da educação superior brasileira tem se projetado mais intensamente nas universidades públicas (PROLO et al., 2019; LEAL, 2019); 2. A vinculação à Faubai sugere que a instituição dispõe de unidade específica responsável por administrar os assuntos relacionados ao processo de internacionalização (LEAL; STALLIVIERI; MORAES, 2017).

Desenvolveu-se um questionário com questões voltadas a compreender: 1. O contexto de sua atuação (tempo de atuação no setor; exercício de cargo de chefia; síntese de atividades desenvolvidas); 2 . Seu entendimento sobre internacionalização da educação superior (definição do processo; pontos positivos e negativos; mudanças observadas no setor, na instituição e na natureza do seu trabalho por conta da intensificação do processo; desafios); 3 . E a (auto)avaliação sobre a sua participação na gestão do processo (nível efetivo de participação nas atividades; perspectivas de contribuição, competências necessárias e desafios; capacitações na área). Dada a natureza qualitativa da pesquisa, deu-se preferência a questões abertas que valorizassem a contextualidade e os próprios discursos 
dos participantes. Os três eixos em evidência se constituíram nas dimensões de análise e guiaram a exposição dos resultados.

Para operacionalizar a pesquisa de campo, seguiu-se este procedimento: 1. Levantamento, no portal da Faubai (http://faubai.org.br/pt-br/instituicoesassociadas/), das universidades públicas federais vinculadas (59 no total, sendo nove da região Norte; quatorze da região Nordeste; seis da região Centro-Oeste; dezoito da região Sudeste e doze da região Sul); 2. Procura, nos portais dos setores de Relações Internacionais das 59 universidades identificadas, de ocupantes do cargo de secretário executivo; 3. Levantamento, nos portais dos setores de Relações Internacionais das 59 universidades, dos contatos (e-mails) dos ocupantes do cargo de secretário executivo. Segundo os portais institucionais explorados, 27 das 59 universidades abrangidas pelo recorte da pesquisa dispõem de secretários executivos lotados em seus setores de Relações Internacionais. Foram enviadas mensagens eletrônicas com o convite para participar da pesquisa em três datas: 11 de junho; 24 de junho de 2019 e 8 de julho de 2019. No total, participaram dezesseis secretários executivos vinculados a doze universidades públicas federais, conforme Quadro 1. Todas as regiões do país foram contempladas.

Quadro 1 - Panorama das instituições e dos sujeitos abrangidos pelo recorte da pesquisa

\begin{tabular}{|c|c|c|}
\hline Região & Instituição e Setor & Quantidade \\
\hline \multirow{2}{*}{ Norte } & Universidade Federal do Pará (UFPA) & 1 \\
\hline & Universidade Federal Rural da Amazônia (UFRA) & 1 \\
\hline Nordeste & Universidade Federal de Pernambuco (UFPE) & 1 \\
\hline \multirow{2}{*}{$\begin{array}{l}\text { Centro- } \\
\text { Oeste }\end{array}$} & Universidade Federal de Goiás (UFG) & 1 \\
\hline & Universidade Federal de Mato Grosso (UFMT) & 1 \\
\hline \multirow{5}{*}{ Sudeste } & Universidade Federal de São João del-Rei (UFSJ/MG) & 2 \\
\hline & Universidade Federal de Viçosa (UFV/MG) & 1 \\
\hline & Universidade Federal de Minas Gerais (UFMG/MG) & 2 \\
\hline & Universidade Federal de Ouro Preto (UFOP/MG) & 1 \\
\hline & $\begin{array}{l}\text { Universidade Federal dos Vales do Jequitinhonha e } \\
\text { Mucuri (UFVJM/MG) }\end{array}$ & 1 \\
\hline \multirow[b]{2}{*}{ Sul } & Universidade Federal de Santa Catarina (UFSC/SC) & 3 \\
\hline & $\begin{array}{l}\text { Universidade Federal de Ciências da Saúde de Porto } \\
\text { Alegre (UFCSPA/RS) }\end{array}$ & 1 \\
\hline
\end{tabular}

Fonte: Elaborado pelos autores (2019). 
Para fins de análise dos dados, as respostas foram organizadas e categorizadas por meio dos tópicos das dimensões de análise, conforme os padrões, as semelhanças e as divergências observadas nos discursos. Com vistas à preservação da identidade dos entrevistados, eles são referenciados como "SE" (SE1 a SE16).

\section{RESULTADOS E DISCUSSÕES}

\subsection{Contexto de atuação}

Relativamente ao contexto de atuação dos secretários executivos abrangidos pelo recorte da pesquisa, buscou-se conhecer: a) o seu tempo de trabalho no setor de relações internacionais; b) se eles exercem cargo de chefia; e c) o padrão geral das atividades desenvolvidas. Quanto ao tempo de atuação, observou-se que, dos dezesseis respondentes, sete $(43,8 \%)$ estão lotados no setor há 1-5 anos; quatro (25\%), há 6-10 anos; quatro (25\%), há mais de 10 anos; e somente um (6,3\%) está há menos de 1 ano. Essa informação sugere que a maioria dos participantes teve a oportunidade de vivenciar transformações em seu ambiente de trabalho relacionadas à internacionalização, tendo em vista a ênfase que as universidades públicas federais passaram a depositar nesse processo, sobretudo com o impulso de programas governamentais com o CsF (2011-2016), o IsF (2012-atual) e o Capes-PrInt (2017-atual). Essa última iniciativa foca diretamente na instituição e, entre seus objetivos, estão "a consolidação dos planos estratégicos de internacionalização no nível institucional", bem como "a promoção de um ambiente internacional nas instituições participantes" (LEAL, 2019, p. 17)4.

Quanto ao exercício de cargo de chefia, cinco (31,3\%) dos dezesseis respondentes dispõem de função gratificada e ocupam os seguintes cargos: a) secretário l; b) coordenador administrativo; c) assessor de parcerias internacionais; d) coordenador de assuntos internacionais; e e) coordenador de mobilidade

\footnotetext{
4 Somente quatro (UFPE, UFMG, UFV e UFSC) das doze universidades estão efetivamente participando do Programa. Todavia, tendo em vista que o edital de seleção restringia a participação de instituições que não fossem de pesquisa (por exemplo, para inscrever-se, elas deveriam ter pelo menos quatro programas de pós-graduação recomendados pela Capes, sendo pelo menos dois com cursos de doutorado), e que 23 das 36 universidades selecionadas são públicas federais, infere-se que as outras oito se candidataram. Para se candidatar, a instituição deveria apresentar um Plano Institucional de Internacionalização.
} 
acadêmica. A comparação entre as atividades gerais desempenhadas pelos respondentes possibilitou observar uma correspondência com os achados de Leal (2014), que inferiu que secretários executivos que ocupam funções de chefia tendem a desempenhar atribuições com maior nível de responsabilidade e complexidade.

Quanto ao padrão geral das atividades desenvolvidas, constatou-se que a quase totalidade dos respondentes executa funções "típicas" do secretário executivo, que correspondem à descrição do cargo e que no geral independem do setor de lotação. As atividades mencionadas com maior recorrência foram: a) assessoria direta à direção (incluindo a sua substituição em situações de ausência); b) agendamento e preparação de reuniões; c) redação de documentos; d) atendimentos; e) gestão da informação e da comunicação institucional (administração do portal e do e-mail institucional do setor, divulgação de notícias, organização e controle do arquivo; elaboração de relatórios etc.); f) gestão de pessoas (controle de férias de funcionários, contratação de estagiários etc.); g) gestão do espaço físico; e h) gestão financeira (compras, pagamento de bolsas; emissão de passagens e diárias etc).

Um segundo rol de atividades segue o padrão das atribuições habitualmente executadas pelo profissional de secretariado executivo nas IFES, mas revela as especificidades do setor de relações internacionais. Por exemplo: a) tradução de documentos e de acordos/convênios internacionais, redação de documentos e comunicação verbal e escrita em idiomas estrangeiros; b) trâmites relacionados a acordos/convênios internacionais; c) organização e recepção de delegações/ comitivas internacionais d) recepção e matrícula de estudantes internacionais; e) organização de eventos/palestras de parceiros internacionais na universidade; e f) coordenação, orientação e divulgação de programas de MAl à comunidade universitária. Finalmente, foram identificadas atividades que pressupõem uma atuação direta do secretário executivo na gestão do processo de internacionalização institucional, tais como: a) participação na comissão de internacionalização e no planejamento estratégico do setor de relações internacionais; b) gestão de acordos/convênios e projetos internacionais (negociação/articulação, formulação e execução); c) coleta e compartilhamento de dados para pesquisas internas e externas, a exemplo de rankings internacionais; d) gestão da MAl; e e) representação da universidade em viagens/eventos internacionais. 


\subsection{Entendimento sobre a internacionalização da educação superior}

Relativamente ao entendimento dos secretários executivos sobre a internacionalização da educação superior, buscou-se conhecer: a) como eles definem esse processo; b) quais os pontos positivos e negativos que atribuem a ele; c) quais as mudanças observadas na universidade e na natureza do seu trabalho por conta da intensificação do processo; e d) quais os principais desafios adjacentes. Constatou-se que os entendimentos dos participantes sobre internacionalização da educação superior variam significativamente, o que ressalta o caráter circunstancial desse processo. Tratando-se de um construto multifocal com significado contextual específico, infere-se que as rotulações apresentadas se relacionam, sobretudo, às experiências e às expectativas dos próprios participantes (WHITSED; GREEN, 2014). Alguns padrões, todavia, puderam ser identificados.

O primeiro deles diz respeito ao elo que os secretários executivos estabelecem entre internacionalização e visibilidade/reputação internacional da universidade. Por exemplo, para SE1, "a internacionalizaão seria promover a inserção internacional da instituição, o aumento da visibilidade e o fortalecimento e o aumento da qualidade das áreas afins [...]". Para SE12, trata-se de "atuação, visibilidade internacional e acolhimento com ênfase em pesquisa" (grifos nossos). Para SE13, "internacionalização é trabalhar para que o nome de nossa instituição se faça conhecido no âmbito internacional como referência de compromisso com a educação de qualidade e do alto nível de qualificação dos membros de nossa comunidade [...]". De fato, a maior inserção da educação superior no paradigma econômico, em parte resultante da redução global do financiamento público para o setor (SOUSA SANTOS, 2011), faz com que as instituições universitárias se vejam obrigadas a responder a "novos imperativos" (SHAHJAHAN, 2016). É nesse contexto que mecanismos de reputação/competição internacional ficam em evidência, mesmo no caso de universidades como as públicas federais brasileiras, cujos propósitos de criação de valor com a internacionalização são antes simbólicos do que de mercado global.

O segundo padrão observado nas percepções dos secretários executivos diz respeito à visão predominantemente positivista e prescritiva que eles têm sobre a internacionalização da educação superior. A única exceção foi o SE6, que fez referência à desigualdade de benefícios colhidos nesse contexto: "Deveria ser uma cooperação que trouxesse benefício a todas as partes envolvidas, com 
o objetivo de somar, no entanto muitas vezes o ganho é unilateral e a troca de fato não existe por uma soberania histórica dos ditos países desenvolvidos". Apesar da estreita relação entre o fenômeno e uma série de questões políticas e éticas, que são contraditórias e contestáveis (STEIN, 2017), de maneira geral os participantes concebem internacionalização como meio para o alcance de objetivos de natureza acadêmica, relacionados principalmente ao aprimoramento da qualidade. Por exemplo, para SE8, "são medidas, no âmbito acadêmico, que visam à troca de conhecimentos e culturas com o intuito de aprimorar práticas dentro das instituições, bem como formar cidadãos globais". Para SE10, "consiste em esforços conjuntos de professores, pesquisadores e administração central para o compartilhamento de saberes e práticas para aperfeiçoamento do conhecimento no sentido lato e universal". Para SE16, "é o processo de integrar às atividades da instituição uma dimensão internacional, visando melhorar a qualidade do ensino e preparar os estudantes para viverem em um mundo cada vez mais global e multicultural".

Tais perspectivas chamam atenção, ainda, pela presença de termos bastante recorrentes na literatura mainstream sobre internacionalização, que tende a justificar a importância e a necessidade desse processo com base em conceitos abstratos como "qualidade", "excelência", "cidadania global" e "multiculturalismo", mas que, ao mesmo tempo, obscurece a sua conformação com a cultura e os valores ocidentais/eurocêntricos, além de não se dedidar às consequências subjetivas desses imaginários dominantes (LEAL; MORAES; OREGIONI, 2018). Por exemplo, um olhar crítico para "cidadania global" possibilita associar esse conceito à noção de cosmopolitismo, projeto que advoga uma "identidade comum" para toda a humanidade, mas que cria a ilusão de um diálogo intercultural e "mascara relações históricas de apropriação, exploração e desigualdade, assim como promove a defesa de uma forma particular de cultura" (LEAL, 2018).

A predominância do viés prescritivo sobre a internacionalização também se manifesta quando os secretários executivos expõem os pontos negativos/ desvantagens e positivos/vantagens que atribuem ao processo. Por exemplo, para SE3, o problema da internacionalização é a "resistência de uma parcela da comunidade em fazer parte deste ambiente". Para SE4, trata-se da "dificuldade em acompanhar o avanço de IES mais destacadas". Em alguns casos, inclusive, os participantes afirmam não haver desvantagens no processo. Por exemplo, nas 
palavras de SE9, "eu só vejo pontos positivos. [...]. Com a internacionalização da Universidade, pode haver troca de informações de técnicas que são utilizadas em um país e desconhecidas no outro". E SE10 afirma: "Não acredito que haja pontos negativos em ampliar visões sobre o mundo". Observa-se, assim, que de maneira geral as percepções sobre internacionalização da educação superior seguem o discurso político dominante que a concebe como "bem incondicional" (MWANGI et al., 2018). As experiências de alguns respondentes, todavia, levamIhes a questionar tal discurso. Por exemplo, para SE6, "de fato não há trocas horizontais, as universidades internacionais vêm até nós por interesse nos recursos amazônicos e nossos saberes, porém não deixam nada de concreto aqui na região, os ganhos em pesquisa ficam nas mãos dos estrangeiros em geral". SE7, por sua vez, menciona a assimetria de oportunidades entre estratos da comunidade universitária: "Pouca mobilidade de servidores" [em referência aos TAEs]; enquanto SE16 argumenta: "Ainda é um processo elitista; competitividade gerada por meio de rankings internacionais e foco mais em números que em resultados; brain drain".

Foi consensual a percepção de que a internacionalização da educação superior ganhou ênfase no contexto institucional e de que essa ênfase tem induzido a mudanças estruturais e pragmáticas nesse contexto. Por exemplo, alguns participantes sugerem que a universidade em que trabalham está caminhando na direção de institucionalizar o processo. SE2 menciona a "busca por delineamento de política interna sobre internacionalização da educação superior". SE15, por sua vez, faz referência à "criação da Diretoria de Relações Internacionais, [com a qual] percebemos uma maior valorização e motivação para contribuir com o crescimento das relações internacionais da universidade". Outros participantes abordam a demanda por formação específica na área diante da ênfase depositada no processo: "A equipe tem buscado se capacitar constantemente para atender às demandas da melhor forma possivel (cursos de línguas, conhecimento sobre refugiados, novas leis etc.)" (SE8).

Constatou-se, ainda, a expansão da internacionalização na estrutura universitária para além da MAl, o que remete à ideia de internacionalização como um processo "abrangente" (HUDZIK, 2011). Por exemplo, SE7 menciona a "busca por ampliar o processo de internacionalização para além da mobilidade de estudantes"; SE8 faz referência ao "oferecimento de disciplinas em outras línguas; tradução para o inglês dos websites da [nome da universidade]; capacitação 
nos Campi; organzação de eventos de divulgação da internacionalização etc.". Outros participantes, finalmente, tratam da participação do corpo docente nas iniciativas do setor de relações internacionais. Por exemplo, para SE14, "o corpo docente da universidade tem demonstrado um crescente interesse em promover ações de internacionalização no âmbito de sua unidade acadêmica ou programa de pós-graduação". SE16 complementa, comentando do "[...] aumento [...] da conscientização dos docentes sobre a internacionalização e maior envolvimento em ações da [nome do setor de relações internacionais]".

Alguns participantes, todavia, ressaltam a precariedade de recursos para lidar com as demandas resultantes da expansão da complexidade do processo. Por exemplo, para SE4, trata-se de "mais trabalho, mais atividades"; SE5 observa o "aumento de demanda de trabalho e falta de profissional qualificado". Para SE13, "há ênfase, mas não existe meio de custeá-lo". A questão do financiamento foi central nas referências aos principais desafios atrelados à internacionalização da universidade e esteve presente na quase totalidade dos discursos. SE6 ressalta "a falta de recursos para promover uma internacionalização ativa [...]". Para SE10, "financiamento certamente é um grande entrave no processo", e SE11 complementa sobre "Sobreviver com os cortes e contingenciamento de recursos orçamentários [...]". Outros três fatores recorrentes foram: a) a falta de engajamento da comunidade universitária na internacionalização (sobretudo do corpo docente), dada a "necessidade" de uma mudança cultural na instituição para lidar com o processo; b) a burocracia e a falta de apoio da gestão para a efetivação das ações; e c) a baixa proficiência em idiomas estrangeiros (sobretudo o inglês). SE16, por exemplo, menciona diversos desses fatores: "Falta de financiamento; falta de proficiência de idioma estrangeiro; falta de engajamento da comunidade universitária; falta de apoio institucional; falta de uma abordagem mais estratégica no planejamento do processo de internacionalização". E10, por sua vez, discorre: "Considerando que Inglês é o idioma universal, há uma minoria de servidores da [nome da Universidade] que dominam o idioma. Há a necessidade de capacitar os servidores nesse sentido e isso envolve interesse por parte dos servidores".

\section{3 (Auto)avaliação da participação na gestão do processo}

Nessa dimensão, buscou-se conhecer como os secretários executivos avaliam a) o seu nível efetivo de participação na gestão da internacionalização 
da universidade; b) as suas perspectivas de contribuição com o processo, as competências que necessitam para tanto e os desafios que enfrentam; c) a sua participação em capacitações na área.

Quanto ao nível efetivo de participação na gestão da internacionalização, observou-se que a maioria dos secretários executivos considera a sua participação alta: em uma escala crescente de 1 a 5 , nove deles (56,3\%) se posicionaram como " 5 " e quatro deles (25\%) se posicionaram como " 4 ", o que condiz com os padrões observados em seus discursos. SE6, por exemplo, explicita como a sua atuação nesse processo tem moldado a própria natureza do seu cargo. Em suas palavras: "o meu trabalho tem se tornado cada vez mais especializado, deixando aos poucos as funções clássicas de secretariado executivo e passando a atuar cada vez mais como uma assessoria especializada em internacionalização". Complementarmente, quando questionados sobre como eles avaliam o papel que eles próprios e outros TAEs ocupam no contexto da internacionalização, eles reconhecem a importância dos seus trabalhos. Por exemplo, para SE3, "O processo de internacionalização é transversal e assim permeia todas as esferas universitárias. Dessa maneira, o papel do TAE é crucial para o bom ou mau desenvolvimento das atividades de internacionalização". SE11 complementa: "Nosso papel é de crucial importância no apoio à internacionalização. Aqui na [nome da universidade] os diretores acreditam na importância da nossa formação específica e têm ações concretas [...] para o desenvolvimento técnico do pessoal".

Apesar desse reconhecimento, alguns deles consideram que os TAEs tendem a ser negligenciados no contexto de internacionalização institucional. Para SE6: "Os técnicos são subvalorizados (internamente) em relação aos docentes gestores das áreas de internacionalização". SE16 complementa: "Os técnicos desempenham um papel muito importante na internacionalização, uma vez que são os responsáveis pelo suporte administrativo às atividades de ensino, pesquisa e extensão da universidade e atuam como facilitadores de processos. Mesmo assim, quando se pensa em internacionalização, lembra-se inicialmente em professores e alunos e, muitas vezes, os técnicos são deixados de lado. É preciso empoderálos e conscientizá-los sobre o papel importante que podem desempenhar na internacionalização".

Quanto às perspectivas de contribuição com o processo de internacionalização e as competências necessárias para que isso se efetive, percebeu-se um consenso 
geral de que o secretário executivo dispõe de boas condições para atuar nesse contexto, o que fornece uma dimensão empírica aos achados teóricos de Leal e Moraes (2017) sobre a correspondência entre as competências do secretário executivo e as competências consideradas pela literatura como necessárias à gestão da internacionalização. Por exemplo, para SE16, "Considerando o caráter multidisciplinar do profissional e seu papel cada vez mais estratégico, o secretário executivo pode ter participação ativa no planejamento estratégico da internacionalização da universidade; atuar como mediador em projetos e programas internacionais e no estabelecimento de novas parcerias; e gerenciar melhorias aos processos organizacionais, visando maior eficiência do setor no desenvolvimento de suas atividades".

Todavia os participantes também enfatizam a necessidade de que recebam formação específica na área, para que possam aprimorar o seu potencial de contribuição. Por exemplo, E2 observa: "Acredito que o secretário executivo é um profissional polivalente e pode atuar em qualquer área da internacionalização da universidade, desde que receba capacitação específica sobre a temática". Entre as competências consideradas pelos secretários executivos como necessárias à gestão da internacionalização, destacaram-se: a) questão linguística (domínio de outros idiomas, capacidade de tradução etc.); b) conhecimento da própria instituição e das leis brasileiras que tratam de questões pertinentes ao processo; c) liderança e o pensamento estratégico; d) gestão de conflitos e inteligência emocional; e e) flexibilidade, disponibilidade, boa relação interpessoal; competência intercultural e diplomacia. Tais competências equivalem em grande medida àquelas que já são atribuídas ao cargo de secretário executivo no contexto das IFES, o que reforça o potencial de que esse profissional contribua com o desenvolvimento do processo.

Quando questionados sobre os principais desafios atrelados ao seu trabalho, os secretários executivos voltam a mencionar fatores relacionados à internacionalização da educação superior de forma geral, o que, de certa forma, sinaliza sua atuação direta na gestão institucional do processo. Os discursos mais recorrentes nesse sentido foram a "resistência" da comunidade universitária, que, segundo os participantes, não está "consciente" da importância da internacionalização, bem como os limites financeiros da universidade. Por exemplo, SE2 menciona: "Resistência por parte dos servidores (docentes e TAEs) em entender a importância desse processo e adequar algumas práticas para 
auxiliar na internacionalização em casa [...]". SE10 complementa: "A falta de entendimento de servidores do que é internacionalização e a importância de que todos os setores da universidade precisam estar envolvidos". As respostas também revelam o quanto o processo avança em termos de institucionalização e abrangência, como se observa no relato de SE4: "Internacionalizar a grade curricular dos cursos de graduação e pós-graduação, expansão dos acordos de formação conjunta e dupla diplomação, aumentar o caráter multilinguístico das ações da [nome da universidade]".

No que se refere à participação dos secretários executivos em capacitações na área de internacionalização, nove dos dezesseis (56,3\%) afirmam ter participado de cursos e eventos nos últimos anos, tais como: a) as conferências da Faubai, do Grupo Coimbra de Universidades Brasileiras (GCUB), da Fulbright e do British Council; b) o programa de formação "Perfeccionamiento en Gestión de la Internacionalización en la Educación Superior" e os webinars da Red Regional para el Fomento de la Internacionalización de la Educación Superior en América Latina (RIESAL-Erasmus+); e c) mobilidades e treinamentos em instituições do exterior, como a Universidade do Porto (Portugal) e a Université de Rouen (França). Observou-se, ainda, que alguns dos participantes realizaram suas pesquisas de mestrado focadas no tema, o que sinaliza a importância designada por tais agentes ao processo.

\section{CONSIDERAÇÕES FINAIS}

O propósito do presente artigo foi conhecer o espaço que o profissional de Secretariado Executivo ocupa na gestão da internacionalização das universidades públicas federais brasileiras. Desenvolveu-se uma pesquisa qualitativa com dezesseis secretários executivos que atuam nos setores responsáveis pela gestão das relações internacionais em doze universidades públicas federais brasileiras, de todas as regiões do país. De maneira geral, os discursos revelaram que tais instituições caminham na direção de institucionalizar o processo, o que suscita o desenvolvimento de estudos que se ocupem de compreender os seus efeitos nesse contexto.

Relativamente ao contexto de atuação, a quase totalidade dos respondentes executa as atribuições "típicas" do seu cargo, mas tais atribuições têm se moldado conforme o desenvolvimento do processo de internacionalização no âmbito institucional. Percebe-se, portanto, uma tendência de ressignificação 
de suas responsabilidades por influência da ênfase que a instituição tem depositado no processo. Cabe pontuar que a institucionalização do processo de internacionalização nas universidades públicas federais brasileiras é recente e que, muito provavelmente, mais transformações nesse sentido poderão ser constatadas nos próximos anos.

Quanto às suas concepções sobre a internacionalização da educação superior, as definições acompanham de maneira significativa a evolução hegemônica do conceito e suas práticas. Constatou-se, por exemplo, a perspectiva "abrangente" implícita na quase totalidade dos discursos; uma visão (eurocentrada) que concebe a internacionalização antes como "imperativo institucional" do que como uma "possibilidade desejável". Segundo essa perspectiva, a internacionalização (a ser antes conduzida conforme os interesses e as prioridades definidos "de cima para baixo" em vez de um como processo construído por vias de participação democrática) é um "bem incondicional" ao qual todos devem se submeter. Há, portanto, o predomínio de uma visão prescritiva, com a exceção de raras referências feitas às contradições e aos dilemas atrelados ao processo.

Finalmente, no que se refere à (auto)avaliação que os secretários executivos fazem de sua participação na gestão da internacionalização, diversos indícios possibilitam inferir que se trata de um profissional cujas competências o possibilitam contribuir com o desenvolvimento do processo. Acrescenta-se, portanto, uma dimensão empírica aos achados de Leal e Moraes (2017). Do ponto de vista instrumental, tanto o contexto promissor de atuação quanto a visão estratégica/pragmática que os secretários executivos têm da internacionalização da educação superior e a (auto)avaliação que fazem de sua participação nesse processo parecem altamente funcionais ao "desenvolvimento" e ao "progresso" da internacionalização no nível institucional.

Todavia é visível a imersão do fenômeno em um paradigma econômico, que faz com que a hierarquia e a desigualdade se consolidem como as suas bases estruturais. Trata-se, em resumo, de um processo que só existe à medida que enfatiza "aquilo que determinada universidade não tem, não faz, não sabe" (MARTINEZ, 2017, p. 78). Dado o avanço da internacionalização de forma hegemônica (LEAL; MORAES; OREGIONI, 2018), cabe fazer um questionamento sobre as perspectivas de que os secretários executivos e as universidades públicas federais contribuam para o desenvolvimento de iniciativas de inserção 
internacional desvinculadas da racionalidade dominante, que desnaturalizem imaginários colonais. Como Sousa Santos (2011, p. 56) recorda, "o único modo eficaz e emancipatório de enfrentar a globalização neoliberal é contrapor-Ihe uma globalização alternativa, uma globalização contra-hegemônica".

\section{REFERÊNCIAS}

BAMBERGER, A.; MORRIS, P.; YEMINI, M. Neoliberalism, internationalisation and higher education: Connections, contradictions and alternatives. Discourse: Studies in the Cultural Politics of Education, v. 40, n. 2, p. 203-16, 2019.

CHILDRESS, L. K. Internationalization plans institutions. Journal of Studies in International Education, v. 13, n. 3, p. 289-309, 2009.

DE WIT, H. Inclusive and innovative internationalization: 25 years of the evolution of a concept. WES-CIHE Summer Institute 2019. Newton: Boston College, 2019.

HUDZIK, J. K. Comprehensive internationalization: from concept to action. 1. ed. Washington, DC: NAFSA, 2011.

HUNTER, F. Training administrative staff to become key players in the internationalization of higher education. International Higher Education, v. 201, n. 92, p. 16-7, 2018.

KNIGHT, J. Internationalization remodeled: definition, approaches, and rationales. Journal of Studies in International Education, v. 8, n. 5, p. 5-31, 2004.

KNIGHT, J. Concepts, rationales, and interpretive frameworks in the internationalization of higher education. In: DEARDORFF, D.; DE WIT, H.; HEYL, J; ADAMS, T. The SAGE Handbook of International Higher Education. Washington, DC: SAGE Publications, 2012.

KNIGHT, J.; DE WIT, H. Preface. Internationalization of higher education: where have we come from and where are we going? In: PROCTOR, D.; RUMBLEY, L. (Ed.). The future agenda for internationalization in higher education: next generation perspectives into research, policy, and practice. New York and London: Routledge, 2018.

LEAL, F. Os caminhos recentes da internacionalização da educação superior brasileira. Revista de Educación Superior en América Latina (ESAL), n. 6, p. 14-18, 2019. 
LEAL, F. Global citizens wanted: cidadania global como construto do imaginário moderno/colonial de internacionalização do currículo. Internacionalização Invertida. Iberoamérica Social. 2018. Disponível em: https://iberoamericasocial. com/global-citizens-wanted-cidadania-global-como-construto-do-imaginariomoderno-colonial-da-internacionalizacao-do-curriculo/. Acesso em: 6 ago. 2020.

LEAL, F. Competências secretariais requeridas pela Universidade Federal de Santa Catarina. 2014. Dissertação (Mestrado em Administração) - Universidade Federal de Santa Catarina (UFSC), Florianópolis, 2014.

LEAL, F.; CÉSPEDES, R.; STALLIVIERI, L. O perfil do gestor universitário de cooperação internacional no Brasil. Revista Eletrônica de Negócios Internacionais (Internext), v. 12, n. 2, p. 1-16, 2017.

LEAL., F; MORAES, M. C. B. M. Decolonialidade como epistemologia para o campo teórico da internacionalização da educação superior. Education Policy Analysis Archives, v. 26, n. 87, p. 1-29, 2018.

LEAL., F; MORAES, M. C. B. M. Perspectivas de atuação do secretário executivo na gestão da internacionalização da educação superior. Revista de Gestão e Secretariado, São Paulo, v. 8, n. 1, p. 138-167, jan./abr. 2017.

LEAL, F.; MORAES, M. C. B. M.; OREGIONI, M. S. Hegemonia e contra-hegemonia no contexto da internacionalização da educação superior: critérios para uma análise crítica e reflexiva do campo. Integración y Conocimiento, v. 7, n. 2, p. 106-32, 2018.

LEAL, F.; SOUZA, S.; MOREIRA, K. D. Atuação do secretário-executivo na gestão universitária pública: o estado do conhecimento sobre a questão. Revista de Gestão e Secretariado, São Paulo, v. 9, n. 1, p. 65-89, 2018.

LEAL, F. G.; STALLIVIERI, L.; MORAES, M. C. B. Indicadores de internacionalização: o que os rankings acadêmicos medem? Revista Internacional de Educação Superior (RIESUp), Campinas, v. 4, n. 1, p. 1-16, 2017.

MARINGE, F.; FOSKETT, N.; WOODFIELD, S. Emerging internationalisation models in an uneven global terrain: findings from a global survey. Compare: A Journal of Comparative and International Education, v. 43, n. 1, p. 9-36, 2013.

MARTINEZ, J. Z. Entre fios, pistas e rastros: os sentidos emaranhados da internacionalização da educação superior. 2017. Tese (Doutorado em Letras) - Universidade de São Paulo, São Paulo, 2017. 
MWANGI, C.; LATAFATAT, S.; KOMMER, S.; THOMA, H.; BERGER, J.; BLANCO-RAMIRO, G. Criticality in international higher education research: a critical discourse analysis of higher education journals. Higher Education, v. 76, n. 6, p. 1091-107, 2018.

PROLO, I.; VIEIRA, R.; LIMA, M.; LEAL, F. Internacionalização das universidades brasileiras: contribuições do Programa Ciência sem Fronteiras. Administração: Ensino e Pesquisa, Rio de Janeiro, v. 20, n. 2, p. 319-61, maio/ago. 2019.

SAID, H.; AHMAD, I.; MUSTAFFA, M. S.; GHANI, F. A. Role of campus leadership in managing change and challenges of internationalization of higher education. Mediterranean Journal of Social Sciences, v. 6, p. 82-88, 2015.

SEEBER, M.; CATTANEO, M.; HUISMAN, J.; PALEARI, S. Why do higher education institutions internationalize? An investigation of the multilevel determinants of internationalization rationales. Higher Education, v. 72, n. 5, p. 685-702, 2016.

SOUSA SANTOS, B. A universidade no século XXI: para uma reforma democrática e emancipatória da Universidade. 3. ed. São Paulo: Cortez Editora, 2011.

SHAHJAHAN, R. A. International organizations (IOs), epistemic tools of influence, and the colonial geopolitics of knowledge production in higher education policy. Journal of Education Policy, n. 31, v. 6, p. 694-710, 2016.

STAFFORD, S.; TAYLOR, J. Transnational education as an internationalisation strategy: meeting the institutional management challenges. Journal of Higher Education Policy and Management, v. 38, n. 6, p. 625-36, 2016.

STEIN, S. Internationalization for an uncertain future: tensions, paradoxes, and possibilities. The Review of Higher Education, v. 41, n. 1, p. 3-32, 2017.

WHITSED, C.; GREEN, W. What's in a name? A theoretical exploration of the proliferation of labels for international education across the higher education sector. Journal of Studies in International Education, v. 18, n. 2, p. 105-19, 2014.

\section{Sobre os autores:}

Fernanda Geremias Leal: Doutoranda em Administração na Universidade do Estado de Santa Catarina (UDESC). Mestre em Administração e bacharel em Secretariado Executivo Inglês pela Universidade Federal de Santa Catarina (UFSC). Pesquisadora visitante no Center for International Higher Education (CIHE), Boston College (BC), 
Estados Unidos. Secretária executiva na Secretaria de Relações Internacionais da UFSC. Conteudista do curso de redação oficial da Coordenadoria de Capacitação de Pessoas da UFSC. Parecerista em periódicos das áreas de estudos organizacionais, educação superior e secretariado executivo. Autora do blog Internacionalização Invertida, junto à Iberoamérica Social: Revista-Red de Estudios Sociales. Integrante do Grupo de Pesquisa sobre a Instituição Universitária (SOCIUS). E-mail: fernanda.leal@ufsc.br, Orcid: http://orcid.org/0000-0002-1716-2060

Raul Oliveira Paes: Mestre em Gestão Pública pela Universidade Federal do Pará (UFPA). Especialista: MBA em Assessoria Executiva pelo Centro Universitário Internacional (UNINTER). Bacharel em Secretariado Executivo Trilíngue pela Universidade do Estado do Pará (UEPA). Servidor público federal, ocupante do cargo de secretário executivo na Escola de Música da UFPA (EMUFPA/UFPA). Tem interesse em pesquisa e trabalho nas seguintes áreas: Assessoria, Gestão Secretarial, Interdisciplinaridade, Secretariado Executivo, Mapeamento de Processos, Gestão Pública, Gestão da Informação e Gestão do Conhecimento. E-mail: rauloliverpaes@gmail.com,Orcid: http://orcid.org/0000-0001-6744-7761

Mário César Barreto Moraes: Doutor em Engenharia de Produção, mestre em Gerência de Engenharia, graduado em Engenharia Civil e em Administração, todos pela Universidade do Estado de Santa Catarina (UDESC). Conselheiro do Conselho Estadual de Educação do Estado de Santa Catarina (CEE-SC). Membro do Conselho Consultivo da Associação Nacional dos Cursos de Graduação em Administração (ANGRAD). Presidente da Comissão Nacional de Avaliação da Educação Superior (CONAES/MEC). Membro da Comissão UNIEDU/FUMDES - Programa de Bolsas Universitárias do Estado de Santa Catarina. Professor titular da UDESC. Tem experiência na área de Administração, Ensino e Estratégia, atuando principalmente nos seguintes temas: administração, educação, avaliação, ensino superior, educação básica e pareceres técnicos na área de educação superior. E-mail: mcbmstrategos@gmail.com, Orcid: http://orcid.org/0000-0002-0760-8444

\section{Recebido em 10 de outubro de 2019. Aprovado em 30 de novembro de 2019.}

